\title{
Transcranial MEP monitoring of vagus nerve
}

\author{
Seokha Yoo ${ }^{1} \cdot$ Won Ho Kim ${ }^{1}$ ] $\cdot$ Jin-Tae Kim ${ }^{1}$
}

Received: 6 January 2019 / Accepted: 26 January 2019 / Published online: 9 March 2019

(c) Japanese Society of Anesthesiologists 2019

Keywords Motor-evoked potentials $\cdot$ Vagus nerve $\cdot$ Thyroid surgery

To the Editor:

We read with great interest the study by Ichino et al. [1], which elegantly reported the feasibility of transcranial motor-evoked potential (MEP) monitoring of vagus nerve during thyroid surgery. We would like to discuss the neuromuscular blockade (NMB) during the MEP monitoring. The authors reported that no additional muscle relaxant was administered after reversal with sugammadex following tracheal intubation. However, sugammadex increases medical cost and no NMB throughout the surgery could cause frequent patient movement and complications such as bite injury of lip, oral mucosa or tongue. A recent study reported a $6.5 \%$ incidence of bite injury when no NMB was used after reversal with sugammadex [2]. A previous study comparing three different levels of partial NMB with no NMB reported that there was no difference in the MEP amplitude between partial NMB and no NMB if careful maintenance of partial NMB target is achieved [3]. We suggest the possibility of partial NBM for MEP monitoring to prevent these complications.

\section{Compliance with ethical standards}

Conflict of interest No competing interest declared.

\section{References}

1. Ichino T, Tanaka S, Tanaka R, Tanaka N, Ishida T, Sugiyama Y, Kawamata M. Transcranial motor-evoked potentials of laryngeal muscles for intraoperative neuromonitoring of the vagus nerve during thyroid surgery. J Anesth. 2019. https://doi.org/10.1007/ s00540-018-2601-x.

2. Yata S, Ida M, Shimotsuji H, Nakagawa Y, Ueda N, Takatani T, Shigematsu H, Motoyama Y, Nakase H, Kirita T, Kawaguchi M. Bite injuries caused by transcranial electrical stimulation motorevoked potentials' monitoring: incidence, associated factors, and clinical course. J Anesth. 2018;32:844-9.

3. Kim WH, Lee JJ, Lee SM, Park MN, Park SK, Seo DW, Chung IS. Comparison of motor-evoked potentials monitoring in response to transcranial electrical stimulation in subjects undergoing neurosurgery with partial vs no neuromuscular block. Br J Anaesth. 2013;110:567-76.

Publisher's Note Springer Nature remains neutral with regard to jurisdictional claims in published maps and institutional affiliations.

This comment refers to the article available online at https://doi. org/10.1007/s00540-018-2601-x.

Won Ho Kim

wonhokim.ane@gmail.com

1 Department of Anesthesiology and Pain Medicine, Seoul National University Hospital, Seoul National University College of Medicine, 101 Daehak-ro, Jongno-gu,

Seoul 03080, South Korea 